\section{Occurrence and Partitioning of Cadmium, Arsenic and Lead in Mine Impacted Paddy Rice: Hunan, China}

\author{
PAUL N. WILLIAMS, ${ }^{\dagger}, \mathrm{MING}^{\ddagger} \mathrm{LI},^{\dagger}$ \\ GUOXIN SUN, ${ }^{\dagger}$ QING HUANG, \\ YING LU, ${ }^{\ddagger}, \perp$ CLAIRE DEACON, \\ A N D RW A. MEHARG, ${ }^{\ddagger}$ A N D \\ Y O N G-GUAN Z H U ${ }^{\dagger, \S, *}$ \\ Research Center for Eco-Environmental Sciences, Chinese \\ Academy of Sciences, Beijing, 100085, China. Institute of \\ Biological and Environmental Sciences, University of \\ Aberdeen, Cruickshank Building, St. Machar Drive, Aberdeen, \\ AB24 3UU, U.K., Institute of Urban Environment, Chinese \\ Academy of Sciences, Xiamen, 361003, China, and College of \\ Natural Resources and Environment, South China \\ Agricultural University, Guangzhou, 510642 China
}

Received August 28, 2008. Revised manuscript received November 9, 2008. Accepted November 19, 2008.

Paddy rice has been likened to nictiana sp in its ability to scavenge cadmium (Cd) from soil, whereas arsenic (As) accumulation is commonly an order of magnitude higher than in other cereal crops. In areas such as those found in parts of Hunan province in south central China, base-metal mining activities and rice farming coexist. Therefore there is a considerable likelihood that lead $(\mathrm{Pb})$, in addition to $\mathrm{Cd}$ and $\mathrm{As}$, will accumulate in rice grown in parts of this region above levels suitable for human consumption. To test this hypothesis, a widespread provincial survey of rice from mine spoilt paddies $(n=100)$, in addition to a follow-up market grain survey ( $n$ $=122$ ) conducted in mine impacted areas was undertaken to determine the safety of local rice supply networks. Furthermore, a specific $\mathrm{Cd}, \mathrm{As}$, and $\mathrm{Pb}$ biogeochemical survey of paddy soil and rice was conducted within southern China, targeting sites impacted by mining of varying intensities to calibrate rice metal(loid) transfer models and transfer factors that can be used to predict tissue loading. Results revealed a number of highly significant correlations between shoot, husk, bran, and endosperm rice tissue fractions and that rice from mining areas was enriched in $\mathrm{Cd}, \mathrm{As}$, and $\mathrm{Pb}$. Sixty-five, 50, and $34 \%$ of all the mine-impacted field rice was predicted to fail national food standards for $\mathrm{Cd}, \mathrm{As}$, and $\mathrm{Pb}$, respectively. Although, not as elevated as the grains from the mine-impacted field survey, it was demonstrated that metal(loid) tainted rice was entering food supply chains intended for direct human consumption.

\section{Introduction}

Human exposure to arsenic (As), cadmium (Cd), and lead $(\mathrm{Pb})$ via the daily rice staple is a concern in some regions,

* Corresponding author phone: +86 10 62936940; fax: +86 10 62936940; e-mail: ygzhu@rcees.ac.cn.

${ }^{\dagger}$ Chinese Academy of Sciences.

‡ Department of Plant and Soil Science, University of Aberdeen.

$\$$ Institute of Urban Environment, Xiamen.

${ }^{\perp}$ South China Agricultural University, Guangzhou. especially within Asia, in areas where farming and mining coexist (1-5). Inorganic As ( $\mathrm{As}_{\mathrm{i}}$ ), a proven group 1 carcinogen (6), is associated with a plethora of insidious diseases affecting fertility in addition to cardiovascular and neurological function (6). Similarly to As, Cd has been linked to pathologies including diabetes, cancers, and high blood pressure (6-8), although it is principally a cumulative nephrotoxicant, that is poorly eliminated by the body with prolonged exposure resulting in renal dysfunction $(4,7)$. In the case of $\mathrm{Pb}$ there is no known no-effect level, and like Cd it can cause kidney failure at both acute and chronic exposures in addition to impacting on cognitive function (9). To safeguard dietary exposure to these metal(loid)s maximum contaminant levels (MCLs) have been set for rice. Surprisingly though, only a small number of countries have an MCL for $\mathrm{As}_{\mathrm{i} . \text {. In }}$ China the upper limit for $\mathrm{As}_{\mathrm{i}}$ in rice is $150 \mathrm{ng} \mathrm{g}^{-1}$ (10). Cadmium and $\mathrm{Pb}$ regulations are more widely endorsed globally, with the Chinese safety thresholds for rice being $200 \mathrm{ng} \mathrm{g}^{-1}$ for both metals, respectively (10).

China has the highest global grain production (11), and with advances in agricultural sciences has maintained grain sufficiency for its 1.3 billion people (12), producing over 184 million tonnes of paddy rice annually; this is despite considerable pressures on water and arable land resources. In parallel with other major rice producing nations, the majority of rice cultivation within China is concentrated in specific key areas. Hunan province (south central China) lies in one such prominent rice producing area, with a largely rural population upward of 65 million, a semitropical climate, and large annual rainfall; it can propagate over 4000 ha of rice (13). Although the cultivation epicenter lies in the north, at the start of the Yangtze river floodplain, rice paddy farming is found throughout the region. The province is also regarded as the heartland of Chinese nonferrous mining. A number of studies have documented severe impacts within Hunan on rice agroecosystems as a result of mining and metal processing activities $(3,14,15)$, although as yet how extensive the problem is has been poorly defined. In particular the safety of local food supply chains in mine-impacted areas has not been adequately addressed.

Soil to plant, and in planta transfer of metal(loid)s is key to risk assessment of mine-impacted rice paddies in China, not just for rice endosperm (polished white rice) but also for straw, husk, and bran. With end uses of these harvested residues as fertilizers, animal feed, building material, and fuel, they play an important role in metal(loid) cycling within arable land systems with resulting consequences for human exposure. Although it is not practical or economically viable to characterize all plant components in widespread rice surveys, developing predictions of likely metal(loid) levels in plant tissue fractions is crucial.

Here we present an extensive province-wide survey of rice from mine impacted areas conducted to determine grain suitability as a constituent of either human or animal diets, by comparing concentrations with national MCLs. In addition, a detailed $\mathrm{Cd}$, As, and $\mathrm{Pb}$ biogeochemical assessment of rice paddies was undertaken to identify important commonalities in metal(loid) transfer and to calibrate models for predicting elemental partitioning in rice.

\section{Materials and Methods}

Survey of Mine Impacted Grain and Market Sourced Rice. Heterogeneity is a prominent feature of rural rice distribution networks within Hunan, with the point source nature of many contaminant pathways, small scale milling practices, and with many areas still largely reliant on local farmers to supply 
their rice needs, determining metal(loid) exposure for the homme moyen is problematic. In this study, it is those with the highest potential risk from the consumption of $\mathrm{Cd}$, As, and $\mathrm{Pb}$ tainted rice that are considered, i.e., those in the vicinity of major mining operations where there is a priori knowledge of severe land degradation (16).

Wholegrain rice, from 100 paddies adjacent to large mining operations, comprised of a composite sample derived from three plants per paddy, were collected. With obvious pollutant source traceability to mine activities these samples allow the extent of rice contamination within Hunan to be gauged in addition to providing information on potential hot spot areas. In total, 12 sites from a variety of different districts were sampled. Four of the areas had prominent lead $(\mathrm{Pb})$ and zinc (Zn) mining concerns: Yizhang (Chenzhou) $(n=6)$, Changningshi (Hengyang) $(n=11)$, Linxiangshi (Yueyang) $(n=12)$, and Shizhuyuan (Chenzhou) $(n=13)$. Two more sites (Qingshuitangqu (Zhuzhou), $n=10$; Daoxian (Yongzhou), $n$ $=11$ ) were within busy metal smelting zones, while the rest represented arable lands close to manganese (Yuetangqu (Xiangtan), $n=7$ ), arsenic (Shimenxian (Changde), $n=13$ ), gold (Heshanqu (Yiyang), $n=10$ ), and antimony (Lengshuijiangshi (Loudi), $n=7$ ) mining operations. To ascertain the potential threat of contamination in the local food supply in these mine impacted areas, 122 polished rice samples intended for direct human consumption were sourced from local shops, markets, and farmers. Ten samples of rice obtained from markets within Hunan, but that were grown outside of the province, were analyzed as a comparison.

Characterization of Metal(loid) Partitioning in Chinese Rice. Four cultivated zones in south-central China with very different soil contaminant loading characteristics were selected (16). A representative value for each zone was obtained by sampling at least five paddy fields in each area. Quadruple paired rice grain, shoot, and soil (0-12 cm depth/ 10-20 g) subsamples, based on strategies adapted from Williams et al. (17) were obtained from each paddy site. Grain, shoot, and root/soil sections were separated in the field. A section of shoot (first $10 \mathrm{~cm}$ of the culm to root base) was discarded to minimize errors associated with soil contamination. In each case the soil collected was directly from under the sampled plants and represented an amalgamation of both rhizosphere and bulk soil.

The most seriously contaminated site, Shuikoushan (Changningshi, Hengyang) in south central Hunan, is located in a prolific lead $(\mathrm{Pb})$ and zinc $(\mathrm{Zn})$ mining belt. Rice production in this area has been significantly reduced in recent years due to human health concerns. The arable lands in and around the northeastern Hunanese site of Qingshuitangqu (Zhuzhou) are subject to a potential contamination risk from the numerous smelteries found in this area. The paddies sampled were in an active agricultural zone bordered by metal processing industries, which supplied grain and vegetables to the nearby city. Two control sites were targeted, one within the Hunan Agricultural University (Furongqu, Changsha), and another from the Yangtze River Delta; both were considered free from mining activities although geogenic levels of $\mathrm{Cd}$, As, and $\mathrm{Pb}$ were expected to be different.

Plant and Soil Sample Preparation and Analysis. Standard multielement methodologies for determining metal(loid) concentrations in soil and rice were adapted from $\mathrm{Zhu}$ et al. (3), Williams et al. (17), and Sun et al. (18) and used throughout; for the the readers convenience, these have been reproduced in the Supporting Information (SI). Readily labile pools of $\mathrm{Cd}$, As, and $\mathrm{Pb}$ from paddy soil-derived dust, corresponding to exchangeable acid and water soluble soil fractions, were estimated by extraction at room temperature of $1.000 \mathrm{~g}$ of soil with $40 \mathrm{~mL}$ of $0.11 \mathrm{~mol}^{-1}$ acetic acid adapted from Rauret et al. (19). Total element detection was achieved using an Agilent 7500a ICP-MS, operated with a babington nebulizer (3). All soil and plant tissue $\mathrm{Cd}$, As, and $\mathrm{Pb}$ concentrations are given on a dry weight basis.

Quality Control. The limits of detection for plant digestions ranged between 0.001 and $0.1 \mu \mathrm{g} \mathrm{Cd} \mathrm{L}^{-1}, 0.001$ and 0.1 $\mu \mathrm{g}$ As $\mathrm{L}^{-1}$, and 0.018 and $0.3 \mu \mathrm{g} \mathrm{Pb} \mathrm{L} \mathrm{Pb}^{-1}$. Limits of detection for soil digests and extractions ranged between 0.04 and 0.1 $\mu \mathrm{g} \mathrm{Cd} \mathrm{L}{ }^{-1}, 0.001$ and $0.19 \mu \mathrm{g}$ As L $\mathrm{L}^{-1}$, and 2.0 and $2.2 \mu \mathrm{g} \mathrm{Pb}$ $\mathrm{L}^{-1}$. Certified reference materials (CRM) 10010 Chinese rice flour and GBW 07405 and 07401 Chinese soils were used to validate the analysis. The average rice flour CRM recovery for Cd ranged from 91 to $103 \%$, whereas for As and $\mathrm{Pb}$ it was 107 and 73\%, respectively. Average recoveries for both soil CRM's ranged from 69 to $100 \%, 97$ to $100 \%$, and 98 to $105 \%$ for $\mathrm{Cd}$, $\mathrm{As}$, and $\mathrm{Pb}$, respectively. Cumulative totals of metal(loid) levels in endosperm and bran fractions were compared with paired wholegrain concentrations. The average recovery ((bran + endosperm/wholegrain $) \times 100), \pm \mathrm{SE}$, was $99 \pm 14 \%, 101 \pm 9 \%$, and $104 \pm 14 \%$, for $\mathrm{Cd}$, As, and $\mathrm{Pb}$, respectively $(n=35)$. Further details for spike recoveries, calibration standards, sample duplication, and chemicals used can be found in the SI.

\section{Results}

Grain Survey (a). The field rice most elevated by Cd, determined from average concentrations, was from Changningshi (Hengyang) followed by Qingshuitangqu (Zhuzhou) $>$ Yuetangqu (Xiantan) > Lengshuijiangshi (Loudi), with median levels in wholegrain rice collected from the Changningshi site being $2272 \mathrm{ng} \mathrm{Cd} \mathrm{g}^{-1}$. The large disparity between mean and median values in Cd grain contents reflects the wide variation in Cd contamination even within a small area. Mean and median As wholegrain levels were similar. Based on median As levels the highest grain averages were found in Shimenxian (Changde) > Lengshuijiangshi (Loudi) > Yizhang (Chenzhou) > Shizhuyuan (Chenzhou) (Table 1). The highest median $\mathrm{Pb}$ grain levels were found at sites in Hengyang and Chenzhou. Both these locations were actively mined for $\mathrm{Pb}$ and $\mathrm{Zn}$.

Levels of grain intended for human consumption were generally lower than for the field survey (Table 1). Rice grain median values for $\mathrm{Cd}$ ranged from $55 \mathrm{ng} \mathrm{Cd} \mathrm{g}^{-1}$ for rice grown outside the province to $332 \mathrm{ng} \mathrm{Cd} \mathrm{g}^{-1}$ in eastern Hunan. For As, the lowest averages were found in northern Hunan areas, whereas grain concentrations in the Chenzhou region were

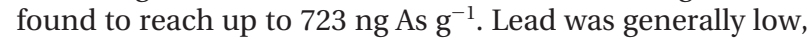
i.e., $<100 \mathrm{ng} \mathrm{Pb} \mathrm{g}^{-1}$; however, a few samples recorded levels of $\sim 1000 \mathrm{ng} \mathrm{Pb} \mathrm{g}^{-1}$ or higher.

Biogeochemical Partitioning (b). Soil. Cadmium. The mean total soil Cd levels in the four different sample sites varied $\sim 140$ fold, from 0.26 to $37 \mu \mathrm{g} \mathrm{g}^{-1}$. The highest recorded soil Cd concentration was $99 \mu \mathrm{g} \mathrm{g}^{-1}$; although uncommon, cultivated paddy soils in southern Asia have been found to reach up to $284 \mu \mathrm{g} \mathrm{g}^{-1}$ (2). In arable soils not severely contaminated by anthropogenic activities such as mining, smelting, or from inputs of Cd tainted fertilizers, global levels should range between 0.1 and $2 \mu \mathrm{g} \mathrm{Cd} \mathrm{g}^{-1}$ (20). Of the total amount of $\mathrm{Cd}$ in the Chinese soils, on average $52 \%$ of the $\mathrm{Cd}$ in Hunan and $19 \%$ of the Yangtze River Delta soils was shown to be labile following weak acid extraction, with levels at Shuikoushan found to be an order of magnitude higher than the global background for total Cd.

Arsenic. At each successive site (Yangtze River Delta, Furongqu, Qingshuitangqu, Shuikoushan), mean total soil As concentrations increased around 3-4 fold, ranging from 6 to $253 \mu \mathrm{g} \mathrm{g}^{-1}$. The highest recorded soil was $321 \mu \mathrm{g} \mathrm{As} \mathrm{g}^{-1}$; equally elevated levels have been documented in miningimpacted agricultural land in southwest England (17). Yangtze River Delta mean levels matched similarly low concentrations found in paddy soils from the east coast province of Fujian 
TABLE 1. Median and 95th Percentile Concentrations of $\mathrm{Cd}$, As, and $\mathrm{Pb}$ in Endosperm Grain Fractions from Mining Districts in Hunan Province, China ${ }^{a}$

\begin{tabular}{|c|c|c|c|c|c|c|c|c|c|c|}
\hline & & & endosper & $d(n g / g)$ & endosper & (ng/g) & endosper & $(n g / g)$ & $n$ & \\
\hline & location & & market & field & market & field & market & field & market/field & mining activity \\
\hline north & Heshanqu & median & 122 & 304 & 126 & 224 & 67 & 51 & $5 / 10$ & $\mathrm{Au}$ \\
\hline & Yiyang & 95th & 309 & 658 & 161 & 585 & 69 & 158 & & \\
\hline & Linxiangshi & median & 123 & 251 & 107 & 196 & 64 & 94 & $13 / 12$ & $\mathrm{~Pb}$ and $\mathrm{Zn}$ \\
\hline & Yueyang & 95th & 276 & 871 & 248 & 348 & 164 & 240 & & \\
\hline & Shimenxian & median & 69 & 84 & 142 & 262 & 68 & 82 & $12 / 13$ & As \\
\hline & Changde & 95th & 107 & 817 & 211 & 483 & 88 & 197 & & \\
\hline middle & Changningshi & median & 330 & 1963 & 229 & 233 & 76 & 784 & $20 / 11$ & $\mathrm{~Pb}$ and $\mathrm{Zn}$ \\
\hline & Hengyang & 95th & 2808 & 2706 & 428 & 483 & 2177 & 197 & & \\
\hline & Lengshuijiangshi & median & & 555 & & 260 & & 107 & 17 & $\mathrm{Sb}$ \\
\hline & Loudi & 95th & & 1351 & & 302 & & 235 & & \\
\hline south & Shizhuyuan & median & $189 *$ & 50 & $232 *$ & 244 & $16^{*}$ & 329 & $10 / 13$ & $\mathrm{~Pb}$ and $\mathrm{Zn}$ \\
\hline & Chenzhou & 95th & $351 *$ & 2757 & $723^{*}$ & 359 & $621 *$ & 537 & & \\
\hline & Yizhang & median & $189 *$ & 32 & $232 *$ & 256 & $16^{*}$ & 171 & $10 / 6$ & $\mathrm{~Pb}$ and $\mathrm{Zn}$ \\
\hline & Chenzhou & 95th & $351^{*}$ & 1243 & $723^{*}$ & 493 & $621 *$ & 329 & & \\
\hline & Daoxian & median & 76 & 71 & 189 & 153 & 109 & 104 & $37 / 11$ & Smeltery \\
\hline & Yongzhou & 95th & 384 & 212 & 355 & 251 & 721 & 329 & & \\
\hline east & Qingshuitangqu & median & 334 & 999 & 218 & 163 & 207 & 166 & $2 / 10$ & Smeltery \\
\hline & Zhuzhou & 95th & 336 & 2492 & 253 & 233 & 261 & 495 & & \\
\hline & Yuetangqu & median & 211 & 694 & 243 & 205 & 24 & 147 & $5 / 7$ & $\mathrm{Mn}$ \\
\hline & Xiangtan & 95th & 1567 & 2644 & 448 & 501 & 1780 & 288 & & \\
\hline west & Huaihua & median & 56 & & 143 & & 67 & & $3 /$ & \\
\hline & Huaihua & 95th & 74 & & 147 & & 67 & & & \\
\hline & Non-Hunan & median & 55 & & 196 & & 16 & & $10 /$ & \\
\hline & & 95th & 183 & & 266 & & 68 & & & \\
\hline
\end{tabular}

${ }^{a}$ Field rice endosperm levels have been predicted from wholegrain concentrations, based on linear regressions (Fig 1.). * combined market rice catchment. A more comprehensive summary of rice metal(loid) levels is presented in the Supporting Information, including addition data from middle Hunan. Data is expressed on a dry weight basis.

$\left(6 \mu \mathrm{g} \mathrm{g}^{-1}\right)(21)$, whereas the Furongqu average was comparable to a control site $\left(18.9 \mu \mathrm{g} \mathrm{g}^{-1}\right)$ used in the Hunan study reported by Liao et al. (15). In Hunan soils only $0.52 \%$ of the total As was readily labile, whereas in the Yangtze River Delta soils, $1.21 \%$ of the total As was deemed mobile.

Lead. Average $\mathrm{Pb}$ concentrations from Shuikoushan soils were 77 times higher than those reported for the Yangtze River Delta, with $3576 \mu \mathrm{g} \mathrm{g}^{-1}$ being the maximum concentration for an individual paddy. Chinese environmental quality standards for $\mathrm{Pb}$ in arable soils are set at $250 \mu \mathrm{g} \mathrm{g}^{-1}$ (16). In both the Pb enriched sites (Qingshuitangqu, Shuikoushan), proportional release of $\mathrm{Pb}$ was greater than the control sites, with $\mathrm{Pb}$ levels at Shuikoushan reaching $14 \%$ of the total.

Shoot. Cadmium levels in all Hunan straw samples obtained in this biogeochemical survey were found to be highly elevated in comparison to those from the Yangtze River Delta. The Shuikoushan site was the most enriched with average levels of $25802 \mathrm{ng} \mathrm{Cd} \mathrm{g}^{-1}$. In addition to high levels of Cd, the straw from Qingshuitangqu and Shuikoushan was elevated in both As and $\mathrm{Pb}$, while levels in the control sites were comparable. Average levels of As from Shuikoushan reached $35417 \mathrm{ng} \mathrm{As} \mathrm{g}^{-1}$. In both contaminated sites, straw concentrations reflected only $15 \pm 4 \%$ of corresponding total soil levels. Although not speciated here, studies suggest that almost all the As found in rice straw is $\mathrm{As}_{\mathrm{i}}(22,23)$. Levels up to $20000 \mathrm{ng} \mathrm{As} \mathrm{g}^{-1}$ in shoot from commercially grown rice in the French Carmargue have been previously documented (17). Lead levels in shoot from Shuikoushan averaged 192466 ng g ${ }^{-1}$; although high, shoot concentrations were $93 \%$ lower than paired soils, a trend that was a feature of all sites.

Husk. There was a 36-fold difference in mean Cd concentrations between Furongqu and Shuikoushan, with all of the husk failing national animal feed hygiene standards

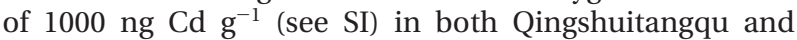
Shuikoushan sites. Arsenic levels in rice husk were similarly high with average levels from Shuikoushan reaching nearly

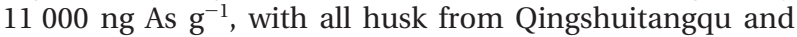
Shuikoushan found unsuitable for animal consumption. $\mathrm{Pb}$ too, was found to be problematic with mean levels of 20776 and $87140 \mathrm{ng} \mathrm{Pb} \mathrm{g}^{-1}$ for the Qingshuitangqu and Shuikoushan sites, respectively.

Bran. The levels of Cd in bran fractions were found to be on average $2.2 \pm 0.5$ times higher than their corresponding endosperm, a trend which was maintained throughout several orders of magnitude in grain $\mathrm{Cd}$, with polishing reducing wholegrain $\mathrm{Cd}$ content by $\sim 12 \%$. No significant difference (general linear model $[\mathrm{GLM}], p=0.633$ ) in the percentage of wholegrain Cd lost by removing the bran was observed between the Hunan rice (Furongqu, Qingshuitangqu, Shuikoushan). The Yangtze River Delta site was found to differ, with the variation being largely attributed to the low concentrations of $\mathrm{Cd}$ found in the associated grain fractions.

Bran As levels were highly elevated in the Hunan collected rice, reaching up to $4074 \mathrm{ng}$ As $\mathrm{g}^{-1}$. Similar concentrations were reported in an As speciation study of Hunan sourced grain (18). Speciation studies of rice bran show the principal species are $\operatorname{As}_{i}(18,24)$. A significant difference (GLM, $p=$ 0.001 ) in the relative proportion of total wholegrain As assimilated in the bran was observed when all the sample sites were considered. When Shuikoushan was removed from the data set, however, no significant difference (GLM, $p=$ 0.444) was observed between the Yangtze River Delta, Furongqu, and Qingshuitangqu sites. Bran from the Shuikoushan accumulated around $\sim 60 \%$ of the total As found in 

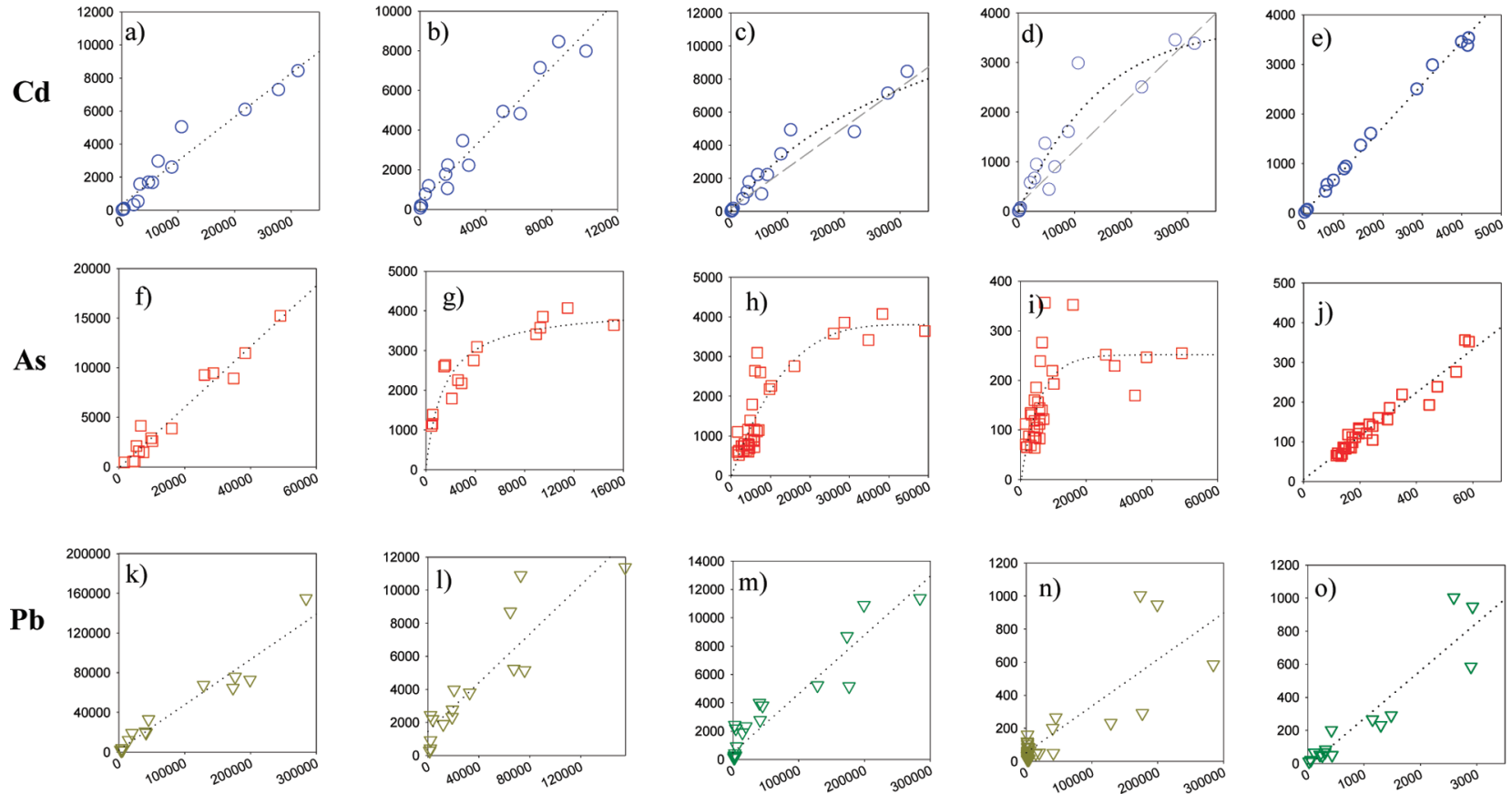

FIGURE 1. South-central Chinese rice aerial biomass transfer relalationships for cadmium, arsenic and lead. Biplots of Cd, As, and $\mathrm{Pb}$ in rice plant tissue. All correlations were statistically significant $(p<0.0001)$. Biplot labels (top) denote $x$-axis first, followed by $y$-axis. $r^{2}$ (a) 0.96 , (b) 0.96, (c) 0.94 [linear] 0.97 [hyperbola], (d) 0.88 [linear] 0.95 [hyperbola], (e) 0.99, (f) 0.95, (g) 0.86, (h) 0.81, (i) 0.52, (j) 0.94 , (k) 0.94, (I) 0.80, (m) 0.90 , (n) 0.70, (o) 0.87 .

the wholegrain, which contrasted with the two control sites where only around $\sim 40 \%$ was assimilated, whereas Qingshuitangqu bran was marginally higher averaging $54 \%$. Bangladesh rice has been reported to store only $\sim 20 \%$ of the wholegrain As in the bran $(18,25)$.

A significant difference (GLM. $p=0.001$ ) was found between bran $\mathrm{Pb}$ : endosperm $\mathrm{Pb}$ ratios between the Hunan sites. In both Qingshuitangqu and Shuikoushan, $75 \%$ of the all the wholegrain $\mathrm{Pb}$ was stored within the bran, whereas for Furongqu and Yangtze River Delta the values were 50 and $64 \%$, respectively. Although still high, with maximum recorded levels of $11377 \mathrm{ng} \mathrm{Pb} \mathrm{g}^{-1}$, the concentrations found in bran from Hunan were much lower than corresponding husk levels. The relative proportions of $\mathrm{Cd}, \mathrm{As}$, and $\mathrm{Pb}$ in bran and endosperm are important when milling is considered.

Endosperm (Polished Rice). The highest Cd levels were found at the Shuikoushan site, with an average value of 3174 $\pm 429 \mathrm{ng} \mathrm{g}^{-1}$. Levels at Qingshuitangqu were less elevated but still high at $1053 \pm 452 \mathrm{ng} \mathrm{g}^{-1}$, whereas Furongqu and the Yangtze River Delta were much lower at $281 \pm 314$ and $5 \pm 7 \mathrm{ng} \mathrm{g}^{-1}$, respectively. Total levels of As did not vary greatly between the three Hunan sites, with an overall mean of $227 \pm 69 \mathrm{ng} \mathrm{g}^{-1}$. The average from the Yangtze River Delta was roughly $50 \%$ lower at $99 \pm 27 \mathrm{ng} \mathrm{g}^{-1}$. Only the Shuikoushan site had highly elevated endosperm levels of $\mathrm{Pb}$, at $612 \pm 69 \mathrm{ng} \mathrm{g}^{-1}$. When compared to national standards 80 and $33 \%$ of the rice from Hunan (Furongqu, Qingshuitangqu, Shuikoushan) failed to meet MCLs for Cd and $\mathrm{Pb}$, respectively. Estimated $\mathrm{As}_{\mathrm{i}}$, derived from total As (3) revealed $7 \%$ of the Hunan samples would exceed the MCL for $\mathrm{As}_{i}$ in rice.

$C d, A s$, and Pb Plant Transfer Dynamics. Soil-Shoot. Median Cd soil-shoot transfer factors (TFs) based on total soil concentrations ranged from 0.25 to 0.95 with no discernible trend found between sites. Soil-shoot TFs from soil to shoot as high as ca. 15 have been observed in Cdaccumulating rice grown in pot experiment conditions (26).
Average soil-shoot TFs of As for the Yangtze River Delta closely matched those of the French Carmargue (17), whereas proportional transfer decreased with increasing total soil As levels and mining impact intensity. Shuikoushan exhibited the lowest transfer at 0.14 . There was little difference between sites in $\mathrm{Pb}$ TFs. Factors ranged from between 2 and 15 fold less than either $\mathrm{Cd}$ or As.

Shoot-Husk. Highly significant $(p<0.0001)$ positive correlations were found for $\mathrm{Cd}\left(r^{2}=0.96\right)$, As $\left(r^{2}=0.96\right)$, and $\mathrm{Pb}\left(r^{2}=0.94\right)$ (Figure 1). With average shoot-husk transfer factors (TFs) being similar for As and Cd at 0.3 , whereas $\mathrm{Pb}$ exhibited a slightly higher value at 0.5 .

Husk-Bran. A correlation of husk and bran Cd levels was also highly significant ( $p<0.001 ; r^{2}=96 \%$ ) closely following a 1:1 relationship throughout the biplot, indicative of possibly similar tissue loading (Figure 1). Lead TFs were $\sim 10$-fold less than reported for $\mathrm{Cd}$, however, the regression was still linear and the correlation highly significant. In contrast to the shoothusk relationship, proportional translocation of As from husk to bran was curtailed at high husk As levels in excess of 4000 $\mathrm{ng} \mathrm{g}^{-1}$ (Figure 1). A similar phenomenon in rice wholegrains was documented in Williams et al. (17) when shoot became elevated in As. It therefore appears that bran and endosperm As transfer is distinct from that of husk, with husk being more closely associated with shoot.

Shoot-Bran. For both $\mathrm{Cd}$ and $\mathrm{Pb}$, strong correlations $(p$ $<0.0001$ ) were found between shoot and bran with $r^{2}$ values of 0.94 and 0.90 , respectively (Figure 1). For As, a nonlinear hyperbola model $\left(f=\mathrm{a}-\mathrm{b} /(1+\mathrm{cx})^{\wedge}(1 / \mathrm{d})\right.$ best explained the data $\left(p<0.0001 ; r^{2}=0.81\right)$, exhibiting the same trend as for husk-bran. Shoot-bran TFs for Pb were around 5-fold lower than for corresponding Cd levels at 0.07 , contrasting with shoot-husk in which $\mathrm{Pb}$ transfer was greater than $\mathrm{Cd}$.

Shoot-Endosperm. TFs were highest for Cd averaging 0.12, which is 4.5 times higher than found for As and $\sim 40$ times higher than for $\mathrm{Pb}$. Biplots of shoot and endosperm $\mathrm{Cd}$ and $\mathrm{Pb}$ produced significant correlations ( $p<0.001, \mathrm{Cd} r^{2}=0.81$, $\mathrm{Pb} r^{2}=0.81$ ), whereas As followed trends observed in shoot- 
bran and husk-bran (Figure 1). The transfer of $\mathrm{Pb}$ from shoot to endosperm is proportionally very small (with a TF of 0.003 ), exhibiting a linear relationship with endosperm and a highly significant correlation. In a comparable survey of As in EU and U.S. rice, median shoot-wholegrain TFs averaged 0.05 for 72 samples (17). This is approximately double the Chinese shoot-endosperm TFs average, and in excellent agreement with overall median shoot-wholegrain TFs found in this study that were 0.04 . Intriguingly though, when the same EU and U.S. data set was compared with Bangladesh grown rice, shoot to grain transfer was significantly higher in the Bengal delta plants (27).

Validation. To assess the shoot-wholegrain transfer models derived from the metal(loid) biogeochemical assessment, data from 29 rice plants grown in Guangdong (adjacent province to Hunan) and analyzed at the University of Aberdeen using ICP-MS (unpublished data) were used as a comparison, see SI. Wholegrain levels of $\mathrm{Cd}$, As, and $\mathrm{Pb}$ were successfully predicted from straw concentrations using the Hunan models; correlations between actual and predicted concentrations were all significant with $r^{2}$ values of $0.98(\mathrm{Cd})$, 0.83 (As), and $0.65(\mathrm{~Pb})$. Median recoveries of predicted against actual values were 113.3, 100.1, 100.1\% for Cd, As, and $\mathrm{Pb}$, respectively.

Predicted levels of endosperm As, derived from the Hunan calibration model using solely wholegrain concentrations were in excellent agreement with those reported in Sun et al. (18) for Hunan rice, yielding recoveries of 83 and $93 \%$ for rice $\mathrm{CH} 1 \mathrm{~A}$ and $\mathrm{CH} 2 \mathrm{G}$, respectively. Similarly for Cd, in 24 paired wholegrain/endosperm rice obtained from Hunan (data from $\mathrm{PhD}$ thesis, in prep) correlations between predicted and actual grain Cd were highly significant ( $p<$ $0.001 ; r^{2}=0.97$ ) with a gradient of 1.06 . Although, modeled levels of $\mathrm{Pb}$ in rice were not validated they were within ranges reported for rice grown in mine impacted paddies in northern Guandong (5).

\section{Discussion}

Grain Survey (a). There is increasing evidence from this and other studies $(3,14-16,28)$ that Cd-, As-, and Pb-tainted paddy soils and rice within Hunan are a common problem in the vicinity of old or currently active large scale mining or ore processing facilities, with mine waste runoff or overspill tainted irrigation water, heavy rainfall induced sediment redistribution, and atmospheric deposition resulting from ore smelting, all contributing to localized land degradation $(14,15)$. With the proliferation of industrial mining, only two regions in Hunan, remain relatively undeveloped, these are the Dongting lake area in the north and the western border, a stretch of land encompassing Shaoyang, Xiangxi, and Zhangjiajie districts.

With wholegrain rice accounting for $\sim 50 \%$ of total animal feed grain consumption in Hunan (29), $78 \%$ of the rice collected from the field met national livestock fodder MCLs for feed, whereas it is predicted that only 26 and $1 \%$ of the bran and husk, respectively, fell within safety limits. It is worth noting that these levels were for washed rice, typically animal food would be unwashed. Using biplots of wholegrain and endosperm metal(loid) levels (Figure 1) in conjunction with estimates of $\mathrm{As}_{\mathrm{i}}$ (3), to predict the levels in the grain after polishing, the same data set was assessed for its suitability for human consumption. It was predicted that 65 , 50 , and $34 \%$ of all the mine impacted field rice would fail national food standards for $\mathrm{Cd}$, $\mathrm{As}$, and $\mathrm{Pb}$, respectively. Although it didn't necessarily concur that grains elevated in one metal(loid) were also high in others. Considering, therefore, that exceeding any MCL warrants the grain unfit for human consumption only 15 out of 100 samples were predicted to be within MCLs for As, Cd, and $\mathrm{Pb}$.
The vast majority of rice consumed in China conforms to national safety standards, which are some of the most stringent globally, for example a survey of 269 polished rice/ endosperm samples collected in 31 districts encompassing six provinces recorded mean $\mathrm{Cd}$ and $\mathrm{Pb}$ levels of $81.4 \pm 65$ $\mathrm{ng} \mathrm{g}^{-1}$ and $113 \pm 65 \mathrm{ng} \mathrm{g}^{-1}$, respectively (30). While the predicted grain $\mathrm{As}_{\mathrm{i}}$ averages for market rice, collected from 11 provinces $(n=230)$ were all under $150 \mathrm{ng} \mathrm{g}^{-1}$ (3). This aside though, a small percentage of contaminated grains are finding avenues into local markets and supply networks in the vicinity of mines. In general, areas found to have the highest metal(loid) levels in the field rice matched those in the local market survey. By using rough geographical classification categories for Hunan and considering MCLs, $17 \%$ of the northern $(n=30), 45 \%(n=47)$ of the southern, $64 \%(n=25)$ of the midlands and $86 \%(n=7)$ of the eastern rice were predicted to not be suitable for human consumption. While all the samples from the west of Hunan and those obtained from local Hunanese markets but that were imported from other provinces, i.e., considered to have originated from nonmetal mining areas, were deemed compliant with $\mathrm{Cd}, \mathrm{As}_{\mathrm{i}}$, and $\mathrm{Pb}$ safety levels.

Biogeochemical Partitioning (b). A number of remarkably clear trends and plant loading commonalities were apparent despite extensive genotypic and environmental variability (Figure 1). The principal sink for metal(loid)s were soil matrixes, however, accumulation in the aerial biomass (i.e., harvested component) was significant representing higher concentrations than labile soil fractions in many instances. Severely elevated levels of $\mathrm{Cd}$, As, and $\mathrm{Pb}$ were a common feature of rice shoots (straw) at all the mine impacted sites, while even background concentrations in Hunan rice appeared higher than other provinces $(3,30)$.

The extent and frequency of elevated levels of endosperm $\mathrm{Cd}$, was the major human dietary exposure concern. In the mine impacted sites average shoot $\mathrm{Cd}$ and As concentrations were similar. Distinct differences were observed, though, in shoot to grain transfer and grain loading characteristics, with shoot-endosperm TFs being 4.5 times higher for Cd than As. The suppression of proportional As transfer from shoot to grain, at high As exposures was demonstrated again to be an important factor in curtailing grain As levels (17). Although, not as pronounced a similar phenomenon appears to in affect for Cd shoot-endosperm transfer when plants are very highly $\mathrm{Cd}$ elevated. However, Cd shoot-bran and husk-bran relationships do not follow those of As. The role of bran as the final interface before endosperm was also crucial, especially for the plants growing in the most heavily contaminated sites. The enormous propensity for Chinese rice to assimilate $\mathrm{Pb}$ and As in the bran was validated here, with bran As content being on average 10-fold higher than corresponding endosperm levels. This was not a situation reciprocated for Cd, though, with wholegrain Cd concentrations decreasing only marginally upon milling.

Typically $\mathrm{Pb}$ concentrations are not high in most plants (20). Seldom do maximum levels in animal feeds exceed 2000

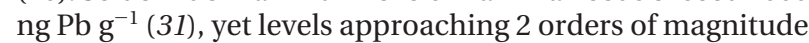
higher were observed during this investigation as potential animal fodder. With root mediated $\mathrm{Pb}$ uptake and transfer unlikely, a direct pathway from soil-shoot/husk is probable. Indeed, with potentially extractable pools of $\mathrm{Pb}$ found to range from 50000 to $392000 \mathrm{ng} \mathrm{g}^{-1}$ in impacted sites, some leaching of $\mathrm{Pb}$ from dust and particulate material depositing on the rice is almost assured.

Being a key deposition site for dust borne contaminants, husk is an effective $\mathrm{Pb}$ scavenger, shown to have a high capacity to adsorb $\mathrm{Pb}$ from aqueous solutions (32). It also, however, shares a close proximity to bran layers, so transfer to wholegrains is tenable. When biplots of husk $\mathrm{Pb}$ against relative titanium ( $\mathrm{Ti}$, is commonly used to ascertain soil 
contamination, see Williams et al. (17)) were considered correlations proved significant, $\left(\mathrm{Pb}, r^{2}=93 ; p<0.0001\right)$. While wholegrain $\mathrm{Pb}$ levels also exhibited a positive relationship $\left(\mathrm{Pb}, r^{2}=23 ; p<0.0001\right)$ albeit a much weaker one, supportive of dust/husk/bran Pb lead fluxes in these severely contaminated sites. In addition to $\mathrm{Pb}$, husk As, and Cd levels correlated significantly with $\mathrm{Ti}\left(p<0.0001\right.$. Cd, $r^{2}=91$; As, $r^{2}=93$ ), with Cd wholegrain not found to share a correlation with $\mathrm{Ti}$, while As was $\left(p<0.0001 . \mathrm{Cd}, r^{2}=57 \%\right)$. Although only circumstantial at the present, this could explain the high proportions of wholegrain As found in bran at the Shuikoushan site.

In conclusion, a series of striking transfer dynamics highlighted the vulnerability of rice to accumulate elevated levels of $\mathrm{Cd}$, As, and $\mathrm{Pb}$ in mine impacted areas. Milling/ polishing rice was shown to dramatically reduce grain As and $\mathrm{Pb}$, but the effect was only marginal for $\mathrm{Cd}$. Two clear $\mathrm{Cd}, \mathrm{As}, \mathrm{Pb}$ exposure pathways, in the form of market rice and animal feed, in mine impacted areas within Hunan province have been identified. Mitigation strategies to curtail body metal(loid) burdens need careful tailoring to meet the needs of impacted communities, and this requires further determination of dose and potential effects to better quantity the risk in exposed populations.

\section{Acknowledgments}

Natural Science Foundation, China (40730740). Chinese Academy of Sciences "Research Fellowship for International Young Researchers" (20070318) and the Royal Society of Edinburgh's International Exchange programme.

\section{Supporting Information Available}

Chemical lists, analytical methodologies, quality control and further data. This material is available free of charge via the Internet at http://pubs.acs.org.

\section{Literature Cited}

(1) Tsuchiya, K.; Iwao, S. Results and evaluation on cadmium intake of Cd-exposed inhabitants in Akita, Ishikawa and Nagasaki Prefectures. Kankyo Hoken Rep. 1978, 44, 86-115.

(2) Simmons, R. W.; Pongsakul, P.; Chaney, R. L.; Saiyasitpanich, D.; Klinphoklap, S.; Nobuntou, W. The relative exclusion of zinc and iron from rice grain in relation to rice grain cadmium as compared to soybean: Implications for human health. Plant Soil 2003, 257, 163-170.

(3) Zhu, Y.-G.; Sun, G.-X.; Lei, M.; Teng, M.; Liu, Y.-X.; Chen, N.-C.; Wang, L.-H.; Carey, A.-M.; Deacon, C.; Raab, A.; Meharg, A. A.; Williams, P. N. High percentage inorganic arsenic content of mining impacted and non-impacted Chinese rice. Environ. Sci. Technol. 2008, 42, 5008-5013.

(4) Band, J. M. R. S.; Senevirathna, D. M. A. N.; Dasanayake, D. M. R. S. B.; Herath, V.; Bandara, J. M. R. P.; Abeysekara, T.; Rajapaksha, K. H. Chronic renal failure among farm families in cascade irrigation systems in Sri Lanka associated with elevated dietary cadmium levels in rice and freshwater fish (Tilapia). Environ. Geochem. Health 2008, doi: 10.1007/s10653-0079129-6.

(5) Yang, Q. W.; Shu, W. S.; Qiu, J. W.; Wang, H. B.; Lan, C. Y. Lead in paddy soils in rice plants and its potential health risk around Lechang Lead/Zinc Mine, Guangdong, China. Environ. Int. 2004, 30, 883-889.

(6) IARC Monographs on the Evaluations of Carcinogenic Risks to Humans; International Agency for Reseach on Cancer: Lyon, France, 2004; Vol. 84.

(7) Satarug, S.; Moore, M. Adverse health effect of chronic exposure to low-level cadmium in foodstuffs and cigarette smoke. Environ. Health Perspect. 2004, 112, 1099-1103.

(8) Haswell-Elkins, M.; McGrath, V.; Moore, M.; Satarug, S.; Walmby, M.; Ng, J. Exploring potential dietary contributions including traditional seafood and other determinants of urinary cadmium levels among indigenous women of a Torres Strait Island (Australia). J. Exposure Sci. Environ. Epidemiol. 2007, 17, 298306.

(9) WHO, EHC. Environmental Health Criteria, Inorganic Lead; International Programme of Chemical Safety: Geneva, 1995.
(10) Maximum Levels of Contaminants in Food, GB 2762-2005; Chinese Food Standards Agency.

(11) FAOSTAT, 2007. Food and Agriculture Organization of the United Nations. http://faostat.fao.org/ (accessed Jan 2008).

(12) Borlaug, N. Feeding a hungry world. Science 2007, 318, 359.

(13) China Statistics 2005. http://www.allcountries.org/china statistics/agriculture.html (accessed Aug 2008).

(14) Liu, H.; Probst, A.; Liao, B. Metal contamination of soils and crops affected by the Chenzhou lead/zinc mine spill (Hunan, China). Sci. Total Environ. 2005, 339, 153-166.

(15) Liao, X.-Y.; Chen, T.-B.; Xie, H.; Liu, Y.-R. Soil As contamination and its risk assessment in areas near the industrial districts of Chenzhou City, Southern China. Environ. Int. 2005, 31, 791798.

(16) Lei, M.; Zeng, M.; Zheng, Y.; Liao, B.; Zhu, Y.-G. Heavy metals pollution and potential ecological risk in paddy soils around mine areas and smelting areas in Hunan Province. Acta Sci. Circ. 2008, 28, 1212-1220.

(17) Williams, P. N.; Villada, A.; Raab, A.; Figuerola, J.; Green, A. J.; Feldmann, J.; Meharg, A. A. Greatly enhanced arsenic shoot assimilation in rice leads to elevated grain export; comparison with wheat and barley. Environ. Sci. Technol. 2007, 41, 68546859.

(18) Sun, G.-X.; Williams, P. N.; Carey, A.-M.; Zhu, Y.-G.; Deacon, C.; Raab, A.; Feldmann, J.; Islam, M. R.; Meharg, A. A. Inorganic arsenic in rice bran and its products are an order of magnitude higher than in bulk grain. Environ. Sci. Technol. 2008, 42, 75427546.

(19) Rauret, G.; Lopez-Sanchez, J. F.; Sahuquillo, A.; Rubio, R.; Davidson, C.; Ure, A. Improvement of the BCR three step sequential extraction procedure prior to the certification of new sediment and soil reference materials. J. Environ. Monit. 1999, $1,57-61$.

(20) McLaughlin, M. J.; Parker, D. R.; Clarke, J. M. Metals and micronutrients-Food safety issues. Field Crop Res. 1999, 60, $143-163$.

(21) Huang, R.-Q.; Gao, S.-F.; Wang, W.-L.; Staunton, S.; Wang, G. Soil arsenic availability and the transfer of soil arsenic to crops in suburban areas in Fujian Province, southeast China. Sci. Total Environ. 2006, 368, 531-541.

(22) Yuan, C.-G.; Jiang, G.-B.; He, B. Evaluation of the extraction methods for arsenic speciation in rice straw, Oryza sativa L., and analysis by HPLC-HG-AFS. J. Anal. At. Spectrom. 2005, 20, $103-110$.

(23) Abedin, M. J.; Cresser, M. S.; Meharg, A. A.; Feldmann, J.; CotterHowells, J. Arsenic accumulation and metabolism in rice (Oryza sativa L.). Environ. Sci. Technol. 2002, 36, 962-968.

(24) Meharg, A. A.; Lombi, E.; Williams, P. N.; Scheckel, K.; Feldmann, J.; Raab, A.; Zhu, Y.-G.; Islam, R. Speciation and localization of arsenic in white and brown rice. Environ. Sci. Technol. 2008, 42, 1051-1057.

(25) Rahman, M. A.; Hasegawa, H.; Rahman, M. M.; Islam, M. N.; Miah, M. A. M.; Tasmin, A. Arsenic accumulation in rice (Oryza sativa $\mathrm{L}$.) varieties of Bangladesh: A glass house study. Water Air Soil Pollut. 2007, 185, 53-61.

(26) Murakami, M.; Ae, N.; Ishikawa, S.; Ibaraki, T.; Ito, M. Phytoextraction by a high-Cd-accumulating rice: Reduction of Cd content of soybean seeds. Environ. Sci. Technol. 2008, 42, 61676172.

(27) Adomako, E. E.; Solaiman, A. R. M.; Williams, P. N.; Deacon, C.; Meharg, A. A. Enhanced transfer of arsenic to grain for Bangladesh grown rice compared to US and EU. Environ. Int. 2008, doi: 10.1016/j.envint.2008.07.010.

(28) Zhai, L.; Liao, X.; Chen, T.; Yan, X.; Xie, H.; Wu, B.; Wang, L. Regional assessment of cadmium pollution in agricultural lands and the potential health risk related to intensive mining activities: A case study in Chenzhou City, China. J. Environ. Sci. 2008, 20, 696-703.

(29) Zhou, Z.-Y.; Tian, W.-M. Grains in China, Foodgrains, Feedgrains and World Trade; Ashgate: Burlington, VT, 2005.

(30) Cheng, F.; Zhao, N.; Xu, H.; Li, Y.; Zhang, W.; Zhu, Z.; Chen, M. Cadmium and lead contamination in japonica rice grains and its variation among the different locations in southeast China. Sci. Total Environ. 2006, 259, 156-166.

(31) Li, Y.; McCrory, D. F.; Powell, J. M.; Saam, H.; Jackson-Smith, D. A survey of selected heavy metal concentrations in Wisconsin dairy feeds. J. Dairy Sci. 2005, 88, 2911-2922.

(32) Wan Ngah, W. S.; Hanafiah, M. A. K. M. Removal of heavy metal ions from wastewater by chemically modified plant wastes as adsorbents. Bioresour. Technol. 2008, 99, 3935-3948.

ES802412R 